\title{
COMPREENDENDO AS RESTRIÇÕES DOS TÉCNICOS DE ENFERMAGEM SOBRE A PERMANÊNCIA DE ACOMPANHANTES EM UNIDADE DE TERAPIA INTENSIVA ABERTA
}

\author{
Carla Ferreira da Luz', Maria Gisleine Melnik², Elizabeth Bernardino ${ }^{3}$, Edinaldo Silva de Oliveira ${ }^{4}$
}

\author{
${ }^{1}$ Graduanda do Curso de Enfermagem da Faculdade de Ciências Biológicas e da Saúde da Universidade Tuiuti do Paraná \\ (UTP). Paraná, Brasil. E-mail: lucafe99@gmail.com \\ ${ }^{2}$ Graduanda do Curso de Enfermagem da Faculdade de Ciências Biológicas e da Saúde da UTP. Paraná, Brasil. E-mail: \\ mariamelnik@bol.com.br \\ ${ }^{3}$ Doutora em Enfermagem. Docente do Curso de Enfermagem da UTP. Paraná, Brasil. E-mail: elizaber@onda.com.br \\ ${ }^{4}$ Enfermeiro. Coordenador da Unidade de Terapia Intensiva do Hospital Pilar. Paraná, Brasil. E-mail: edi-@uol.com.br
}

RESUMO: A presente pesquisa teve como objetivo compreender as restrições dos técnicos de enfermagem sobre a permanência de acompanhantes em Unidade de Terapia Intensiva. Trata-se de uma pesquisa qualitativa do tipo exploratória. Os sujeitos foram 11 técnicos de enfermagem de todos os turnos. A coleta de dados se deu em dois encontros no mês de março de 2008. Para a análise, foi utilizada a técnica do Discurso do Sujeito Coletivo. Após análise foi possível apreender duas ancoragens: a Ancoragem I mostra que os acompanhantes representam uma sobrecarga para os técnicos e a Ancoragem II que os técnicos se sentem desprotegidos em relação aos familiares. Conclui-se que as razões que supostamente geram o conflito não é a relação com o acompanhante ou o desenvolvimento de técnicas sob observação, mas a pouca valorização profissional e a falta de suporte para executar as atividades diárias.

DESCRITORES: Unidades de terapia intensiva. Relações profissional-família. Equipe de enfermagem. Acompanhantes de pacientes.

\section{UNDERSTANDING NURSING TECHNICIANS' OBJECTIONS TO PATIENTS' COMPANIONS STAYING IN THE INTENSIVE CARE UNIT}

\begin{abstract}
The objective of this qualitative, exploratory research was to better understand nursing technicians' objections to patients' companions staying in the Intensive Care Unit. The subjects were 11 nursing technicians from all shifts. Data was collected in two meetings in March, 2008. The Discourse of the Collective Subject technique was used for analysis. After analysis, 2 main ideas (or anchor ideas) were apprehended: Anchor idea I shows that patients' companions represent a burden for technicians, and Anchor idea II shows that technicians feel unprotected in relation to them. It is concluded that the reasons which supposedly generate the conflict are not the relationship with the companion or the development of techniques under observation, but the professional undervaluing and the lack of support to perform daily tasks.
\end{abstract}

DESCRIPTORS: Intensive care units. Professional-family relations. Nursing, team. Patient escort service.

\section{COMPRENDIENDO LAS RESTRICCIONES DE LOS TÉCNICOS EN ENFERMERÍA ANTE LA PERMANENCIA DE ACOMPAÑANTES EN UNIDAD DE TERAPIA INTENSIVA ABIERTA}

RESUMEN: La presente investigación tuvo como objetivo comprender las restricciones de los técnicos en enfermería ante la permanencia de acompañantes en la Unidad de Terapia Intensiva. Se trata de una investigación cualitativa, de tipo exploratorio. Los sujetos fueron 11 técnicos en enfermería de todos los turnos. La recolección de los datos se realizó mediante dos encuentros en el mes de marzo de 2008. Para el análisis se utilizó la técnica del Discurso de Sujeto Colectivo. Con el análisis fue posible reconocer dos tópicos : el Tópico I, revela que los acompañantes representan una sobrecarga para los técnicos, y el Tópico II muestra que los técnicos se sienten desprotegidos frente a ellos. Se concluye que las razones que supuestamente generan el conflicto no es la relación con el acompañante o el desarrollo de técnicas de observación, sino la poca valorización profesional y la falta de apoyo para ejecutar las actividades diarias.

DESCRIPTORES: Unidades de terapia intensiva. Relaciones profesional-familia. Grupo de enfermería. Acompañantes de pacientes . 


\section{INTRODUÇÃO}

A Unidade de Terapia Intensiva (UTI) vem sofrendo transformações com o surgimento de intervenções que são recomendadas e implementadas na unidade, dentre elas, a permanência constante do acompanhante junto ao cliente internado, como uma maneira de proporcionar conforto e diferencial de qualidade. ${ }^{1}$

Até 10 anos atrás, a Enfermagem visava exclusivamente o cliente, dando ênfase em sua evolução, observação e monitoramento de complicações, excluindo todo o seu contexto social, deixando a família em segundo plano. ${ }^{2}$ Com o tempo, percebeu-se que a família pode contribuir e interagir com a equipe, favorecendo o tratamento e influenciando na recuperação emocional do paciente. ${ }^{3} \mathrm{~A}$ intervenção familiar no tratamento tem sido cada vez mais freqüente, em função do nível de conhecimento que as pessoas possuem, de uma maneira geral, sobre os seus direitos.

É reconhecidamente difícil, para o familiar, ter alguém internado em UTI. Muitos gostariam de permanecer todo o tempo com os seus, mas a maioria das UTIs possui regras rígidas com controle de visitas.

As políticas de humanização do Governo Federal têm favorecido algumas categorias de pacientes como as crianças, ${ }^{4}$ as gestante ${ }^{5}$ e os idosos, ${ }^{6}$ no que se refere à presença de acompanhantes em unidades de internação. Nas UTIs, entretanto, as que possuem mais avanços são as Pediátricas e Neonatais, sendo as adaptações brasileiras do Método Canguru um bom exemplo de humanização para recém-nascidos de baixo peso. ${ }^{7} \mathrm{~A}$ instabilidade clínica do cliente, o aparato tecnológico, a complexidade dos cuidados e o risco de infecção são alguns dos motivos alegados pelos dirigentes e profissionais das UTIs para não autorizarem acompanhantes todo o tempo.

A facilidade de acesso ao conhecimento, as novas exigências do consumidor e as políticas de humanização do cuidado podem estar socializando discussões sobre vantagens e desvantagens da presença de acompanhantes, fazendo com que alguns serviços façam investimentos nesta área. Há dúvidas se a equipe de saúde, incluindo a Enfermagem, já está preparada para atender adequadamente aqueles acompanhantes que permanecem todo o tempo com o paciente.

A permanência de acompanhantes nas 24 horas com o paciente, UTI aberta, pode ser considerada uma inovação. Em 2007, foi desenvol- vido um estudo em uma instituição privada, que possuia leitos de UTI aberta, sobre os limites e as possibilidades da permanência de acompanhantes na unidade. ${ }^{8}$ Responderam ao questionário 42 funcionários e 20 acompanhantes. Os resultados mostraram que os acompanhantes se sujeitam bem às normas estabelecidas, como uma condição de sua permanência. Mesmo reconhecendo os benefícios de acompanhantes para os pacientes, os funcionários relataram algumas restrições, dentre as quais, seu próprio despreparo em lidar com a família.

Esta pesquisa foi realizada no mesmo cenário e tomou como ponto de partida, os resultados da pesquisa anterior ${ }^{8}$ no que concerne às dificuldades e as restrições dos técnicos de enfermagem em aceitar a presença de acompanhantes. Os estudos que tomam como objeto o trabalho em equipe, a partir da percepção dos técnicos e auxiliares fornecem elementos importantes para os enfermeiros refletirem e aprimorarem a coordenação do trabalho da equipe na enfermagem. ${ }^{9}$

Considerando que esta proposta tende a continuar neste hospital, esta pesquisa teve o objetivo de compreender as restrições dos técnicos de enfermagem sobre a permanência de acompanhantes em UTI aberta.

\section{MÉTODO}

Este é um estudo qualitativo do tipo exploratório. A pesquisa exploratória se inicia com algum fenômeno de interesse, no qual se investiga a sua natureza complexa e os métodos qualitativos são especialmente úteis para a exploração destes fenômenos. ${ }^{10}$

O estudo foi realizado em uma UTI, do sul do Brasil, que possui 33 leitos dos quais 17 são leitos de UTI aberta. A força de trabalho da enfermagem, exclusivamente para esta UTI, é composta por um coordenador de enfermagem, cinco enfermeiros e 48 técnicos de enfermagem.

Os sujeitos da pesquisa foram 11 técnicos de enfermagem sendo 10 do sexo feminino e um do sexo masculino, lotados nos leitos de UTI aberta, de todos os turnos, que aceitaram voluntariamente participar da pesquisa. A amostra foi delimitada pelo interesse e disponibilidade dos participantes. Fez-se uma opção por só trabalhar com este profissionais porque são em maior número, porque são os que ficam a maior parte do tempo com os acompanhantes e porque foi identificado, na pesquisa anterior, maior resistência a esta proposta. Os critérios de inclusão foram, portanto, ser técni- 
co de enfermagem deste hospital, estar lotado na UTI aberta, e aceitar participar da pesquisa.

A coleta de dados foi realizada durante o mês de março de 2008, em dois encontros, no auditório do hospital, por meio de uma entrevista coletiva. O primeiro encontro foi gravado, teve duração de uma hora e meia, e foi transcrito posteriormente. Após a composição do grupo, foi explicado o projeto, os sujeitos foram identificados por letras, assinaram o Termo de Consentimento Livre e Esclarecido e responderam a seguinte questão: "o que os acompanhantes significam para vocês no seu trabalho cotidiano?"

O segundo encontro aconteceu 15 dias após o primeiro e foi apresentado, ao mesmo grupo, os resultados da pesquisa. Os técnicos de enfermagem tiveram, então, a oportunidade de discutir e confirmar os achados do primeiro encontro.

Para a análise dos dados utilizou-se a técnica do Discurso do Sujeito Coletivo (DSC) que é uma proposta de organização e tabulação de dados qualitativos de natureza verbal, a qual orienta o pesquisador a fazer perguntas abertas para um conjunto de indivíduos que representam, de alguma forma, uma coletividade e deixar que estes indivíduos se expressem livremente. ${ }^{11}$

Para confeccionar os DSCs, foram extraídas dos discursos as Expressões-chave $(\mathrm{ECH})$ que são trechos ou pedaços do conteúdo discursivo que revelam a essência do depoimento. As ECHs deram origem às Idéias Centrais (ICs) que são uma descrição de um conjunto de depoimentos, das quais obtiveram-se as Ancoragens (ACs) que, na qualidade de afirmação genérica, está sendo usada para "enquadrar" uma situação específica. ${ }^{11}$

A pesquisa atendeu a Resolução Nº 196/96 ${ }^{12}$ no que concerne aos aspectos éticos, sigilo das informações, garantia de anonimato e confiabilidade dos dados e foi aprovada pelo Comitê de Ética em Pesquisa da Universidade Tuiuti do Paraná sob $\mathrm{N}^{\circ} 0113 / 2007$.

Os termos familiares e acompanhantes serão aqui usados indistintamente, uma vez que consideramos que os acompanhantes podem ou não ser familiares.

\section{RESULTADOS E DISCUSSÃO}

A análise das ECHs dos discursos originais permitiu apreender sete IC(s) as quais agrupadas, originaram duas ACs. A ancoragem I: Os familiares representam uma sobrecarga para os técnicos de enfermagem e a ancoragem II: Os técnicos se sentem desprotegidos em relação aos familiares.

A discussão e apresentação dos DSCs serão feitas a partir de cada AC.

A AC I, "os familiares representam uma sobrecarga para os técnicos de enfermagem", possui quatro ICs as quais são apresentadas com seus respectivos discursos no Quadro 1.

Quadro 1 - Idéias centrais da ancoragem I e seus respectivos discursos do sujeito coletivo. CuritibaPR, 2008

\begin{tabular}{|l|l|}
\hline \multicolumn{1}{|c|}{ Idéias centrais da ancoragem I } & \multicolumn{1}{c|}{ Discursos do sujeito coletivo } \\
\hline $\begin{array}{l}\text { 1. Os técnicos precisam explicar todos os } \\
\text { procedimentos aos familiares. }\end{array}$ & $\begin{array}{l}\text { Os familiares se assustam com os procedimentos que devemos fazer, } \\
\text { eles os acham muito agressivos, temos de explicar e acalmar a cada } \\
\text { procedimento. A regra é eles saírem do quarto, mas nem sempre eles o } \\
\text { fazem (DSC1). }\end{array}$ \\
\hline $\begin{array}{l}\text { 2. Os familiares não possuem suporte emo- } \\
\text { cional para ficar em um ambiente de UTI. }\end{array}$ & $\begin{array}{l}\text { Há familiares que conseguem ficar perto dos pacientes, outros se agi- } \\
\text { nhante e algumas vezes eles deixam os pacientes mais agitados e com } \\
\text { alteração de PA (DSC2). }\end{array}$ \\
\hline $\begin{array}{l}\text { 3. Os familiares são muitos e cada um é } \\
\text { diferente do outro. }\end{array}$ & $\begin{array}{l}\text { Os acompanhantes fazem rodízio, então é muita rotatividade, cada turno } \\
\text { é um, às vezes têm 10 em um dia e chegam com problemas, cansa- } \\
\text { dos, depende de quem aparece temos de repetir todas as informações" } \\
\text { (DSC3). }\end{array}$ \\
\hline $\begin{array}{l}\text { 4. Sugestões para minimizar a sobrecarga } \\
\text { causada pelos familiares na UTI. }\end{array}$ & $\begin{array}{l}\text { Algumas medidas já foram tomadas como fixar as equipes e escolher o } \\
\text { funcionário com melhor perfil para atender acompanhantes. Achamos } \\
\text { que deveriam fazer uma melhor seleção, tanto dos pacientes que real- } \\
\text { mente necessitam de acompanhantes como dos acompanhantes que } \\
\text { têm condições de ficar com os pacientes. Uma boa opção seria só per- } \\
\text { manecer de dia quando há mais suporte para atendê-los ou melhorar o } \\
\text { suporte à noite (DSC4). }\end{array}$ \\
\hline
\end{tabular}


O DSC1, no que concerne ao fato de que os técnicos precisam explicar todos os procedimentos aos familiares, duas questões são importantes nesta discussão: a primeira é se a equipe de enfermagem está preparada para fornecer informações adequadas e condizentes com o nível de entendimento dos familiares e a segunda é se a administração previu a adição deste trabalho às atividades cotidianas dos técnicos.

Os familiares não estão preparados para ver seu ente querido sedado e com tantos equipamentos, ficam chocados com o cenário e desesperados com a situação. ${ }^{13}$ A cartilha do Programa Nacional de Humanização ${ }^{14}$ que trata sobre a visita aberta e direito a acompanhante afirma, em um exemplo, que ao instituir um espaço diário de conversa com os acompanhantes, uma instituição mudou radicalmente a atitude destes no ambiente de cuidado. De uma postura passiva e, muitas vezes, agressiva passaram a de cooperação para com o coletivo e manutenção das combinações.

O DSC2, neste aspecto, mostra claramente o quanto é difícil para o familiar lidar com este aporte tecnológico na mesma proporção que este fato é naturalizado pelos técnicos de enfermagem, pois para eles, todo este aparato, nada mais é que instrumentos do seu trabalho. Isto mostra como os dois grupos de atores (familiares e técnicos) percebem estas tecnologias (equipamentos e procedimentos) diferentemente. Os familiares com desconfiança, pois, os equipamentos e procedimentos parecem instrumentos de tortura e, para os técnicos, estes são apenas necessários à execução de suas tarefas.

O DSC3 exemplifica que, em função da rotatividade de acompanhantes, os técnicos têm de interromper suas atividades inúmeras vezes, o que acarreta um atraso nas tarefas de rotina, as quais implicarão em outras queixas por parte de outros pacientes. Mesmo quando não há procedimentos, os acompanhantes solicitam a todo o tempo os técnicos, pois se assustam com barulhos, bips, sangue e toda e qualquer alteração. As explicações e interrupções ocasionam direta ou indiretamente, sobrecarga e estresse para o funcionário, pois ele tem que dar conta de todas as atividades antes do término do plantão.

Observamos que pode haver um despreparo do técnico em lidar com as situações trazidas pelos acompanhantes, mas nem sempre há pessoal suficiente para absorver esta atividade. Muitas vezes trabalha-se com escalas reduzidas e o funcionário tende a deixar os familiares/acompanhantes em um papel secundário, hierarquizando o atendimento, com prioridade para o paciente e não para o acompanhante.

Como referido pelos técnicos de enfermagem, alguns familiares conseguem ficar perto, outros se agitam e ficam nervosos, levando os funcionários a ter de atendê-los também. Este discurso mostra que os acompanhantes/familiares devem ser bem esclarecidos e avaliados se sua presença terá resultado positivo sobre o paciente e sobre ele mesmo.

Neste sentido, o hospital prevê uma avaliação pela assistente social, porém muitas vezes, o acompanhante/familiar superestima sua capacidade emocional e, no cotidiano, os problemas se sobrepõem e as crises físicas, psicológicas, emocionais afloram. A imprevisibilidade das reações dos familiares deve ser incorporada como mais um aspecto da permanência de familiares a ser monitorado.

Para que haja um bom desempenho entre as equipes, considera-se importante uma seleção na admissão do familiar. Esta triagem poderá ser realizada antes da admissão ou durante sua estada na primeira semana e deverá ser em conjunto com a equipe multidisciplinar (assistente social, psicóloga, enfermeiro e médico), a fim de identificar aquele com suporte emocional para dar assistência a seu familiar hospitalizado. ${ }^{15}$

Sobre este comentário é importante ressaltar que o atendimento humanizado precisa ser entendido como responsabilidade de cada pessoa e não dever exclusivo de uma classe profissional, pois nenhuma categoria por si só consegue se apropriar do paciente, na sua totalidade dentro do processo saúde-doença. ${ }^{16}$

O DSC4, referente às sugestões, mostra que algumas medidas tomadas foram eficazes como a fixação da equipe nos leitos de UTI aberta. Neste mesmo discurso, os técnicos de enfermagem relatam que falta ainda melhorar a avaliação do paciente que necessita de acompanhante e dos acompanhantes com condições de permanecer com os pacientes.

Podemos esperar melhor resultado com os enfermeiros fazendo esta ponte entre a família e a equipe de enfermagem, esclarecendo, por meio de comunicações claras e simples, pois os erros de comunicação podem gerar conflitos. ${ }^{17} \mathrm{O}$ investimento em algumas estratégias para diminuir este encargo dos funcionários pode trazer bons 
resultados, pois o trabalho estressante sem planejamento das atividades, desenvolve um desgaste, cansaço e sobrecarga. ${ }^{15}$
$\mathrm{Na}$ AC II, os técnicos de enfermagem referem o quanto eles se sentem desprotegidos em relação à família (Quadro 2).

Quadro 2 - Idéias centrais da ancoragem II e seus respectivos discursos do sujeito coletivo. CuritibaPR, 2008

\begin{tabular}{|l|l|}
\hline \multicolumn{1}{|c|}{ Idéias centrais da ancoragem II } & \multicolumn{1}{c|}{ Discursos do sujeito coletivo } \\
\hline $\begin{array}{l}\text { 1. As regras para os acompanhantes } \\
\text { são relativas. }\end{array}$ & $\begin{array}{l}\text { Existem regras, porém elas não valem para todos, dependendo do acompa- } \\
\text { nhante eles falam no celular, tiram fotos, ficam deitados com paciente, an- } \\
\text { dam sem avental, etc. Se forem médicos ou parentes de médicos aí piora, } \\
\text { porque eles não aceitam seguir regras. Também quando uma familia briga } \\
\text { muito ou insiste, a UTI acaba cedendo (DSC5). }\end{array}$ \\
\hline $\begin{array}{l}\text { 2. Os técnicos de enfermagem têm } \\
\text { pouca autonomia para resolver proble- } \\
\text { mas com familiares. }\end{array}$ & $\begin{array}{l}\text { Nós temos pouca autonomia pois somos proibidos de falar diretamente com } \\
\text { os médicos e temos de usar o enfermeiro como intermediário. Os médicos } \\
\text { nem sempre respondem aos chamados das familias e a enfermeira nem } \\
\text { sabilidade de responder às solicitações da família, sem termos respaldo. } \\
\text { Somos uma equipe multiprofissional, deveríamos poder falar com os médi- } \\
\text { cos, pelo menos nas questões mais simples para agilizar; não somos des- } \\
\text { preparados, somos desprotegidos (DSC6). }\end{array}$ \\
\hline $\begin{array}{l}\text { 3. Os familiares valorizam muito pouco } \\
\text { o trabalho do técnico de enfermagem. }\end{array}$ & $\begin{array}{l}\text { Temos a impressão que somos pouco reconhecidos. Alguns familiares fal- } \\
\text { tam com o respeito conosco porque acham que são os convênios que nos } \\
\text { pagam e que somos empregados deles. Alguns também dizem que não } \\
\text { atendemos, não fizemos o procedimento e tal e eles têm muito peso. Já } \\
\text { houve casos que o meu colega me viu fazendo o procedimento e me aju- } \\
\text { dou. Por isso marcamos presença, acendendo a luz, acordando, falando } \\
\text { com eles, para evitar estes problemas (DSC7). }\end{array}$ \\
\hline
\end{tabular}

O DSC5 revela que, nem sempre os acompanhantes/familiares obedecem às regras, mesmo que elas sejam claras, sobretudo para pacientes cujos acompanhantes/familiares são médicos. Neste caso específico, podemos considerar a baixa defesa que as outras profissões possuem em relação a esta categoria, o que pode gerar alguns conflitos. Os relacionamentos conflituosos entre médicos, enfermeiros e técnicos de enfermagem são provavelmente relacionados ao contexto histórico, entre as três categorias profissionais, na qual prevalece a supremacia médica. ${ }^{18}$

O que talvez possa interferir na dificuldade dos acompanhantes/familiares respeitarem as normas é a natureza privada desta UTI. Em estudo realizado recentemente com acompanhantes de UTI de hospital público e privado, evidenciou-se que as famílias de pacientes internados possuem medos, inseguranças e necessidades semelhantes, independente de questão social ou financeira, mas a preocupação com o cuidado do familiar emergiu na UTI do hospital privado. ${ }^{19}$

Possivelmente eles tenham dificuldade de compreender que as normas existem para proteger o paciente e favorecer o trabalho da equipe seguindo um principio científico. Se os dirigentes do hospital não tiverem êxito nas explicações, a não observação destas regras pode sobrecarregar os funcionários. Neste caso, a comunicação, a observação e a permanência contínua do acompanhante e às orientações facilitam a participação do acompanhante no convívio hospitalar. ${ }^{3}$

O DSC6 traz a insuficiência numérica do profissional enfermeiro para realizar esta mediação de conflitos e a falta de autonomia percebida pelos técnicos de enfermagem. Esta falta de autonomia é sentida mais porque há uma hierarquia a seguir, principalmente nos encaminhamentos que dizem respeito aos acompanhantes/familiares, e não para executar atividades mais técnicas.

Nas UTIs existe uma hierarquia rígida, estabelecida pelo grau de escolaridade de cada um dos elementos da equipe de enfermagem, na qual a enfermeira fica no topo da cadeia de comando. ${ }^{9}$ Aparentemente, a demanda dos familiares é grande também para os outros profissionais, porém, os técnicos de enfermagem são muito solicitados e não conseguem ter a mesma resolutividade. Nestas unidades, como as relações interpessoais não são devidamente valorizadas e adequadamente 
trabalhadas, os trabalhadores de enfermagem se desgastam intensamente para suportarem a convivência grupal no cotidiano de trabalho e, ainda, vivem o temor de que os conflitos intragrupais possam afetar o cuidado ao paciente. ${ }^{9}$

Desta forma, aparece um sentimento de exclusão das decisões relativas aos acompanhantes/familiares. Isto se deve, em parte, à pouca valorização do trabalho dos técnicos de enfermagem pelos familiares, ${ }^{20}$ relatada no DSC7. Neste discurso observa-se que, diante de experiências vivenciadas nas quais o familiar duvidou da ação do técnico e que este não foi apoiado pela instituição; houve quebra de confiança entre as partes, o que ocasionou o desenvolvimento de formas particulares de defesa do trabalhador, o qual precisou marcar presença, para o familiar, durante os procedimentos.

O fato de valorizarmos a experiência dos acompanhantes/familiares como singular, reconhecendo que cada família tem seu modo próprio de lidar com a situação da internação ajuda, mas não diminui o impacto no trabalho e neste sentido é a organização do trabalho que deve tentar diminuir este impacto, sensibilizando para a dimensão subjetiva do cuidado.

\section{CONSIDERAÇÕES FINAIS}

Os resultados mostram que além dos técnicos de enfermagem se sentirem sobrecarregados com os pacientes, também se sentem desprotegidos. Percebemos que a falta de defesas coletivas torna o ambiente estressante e inseguro para a equipe. Alguns resultados já são conhecidos, tais como o poder do médico sobre o processo de trabalho em saúde, a falta de autonomia do técnico de enfermagem e a pouca valorização do trabalho do técnico perante os demais membros da equipe e da família.

Com relação à sobrecarga causada pelos acompanhantes/familiares, as providências tomadas foram importantes, como a fixação de funcionários na UTI aberta, mas não suficientes para melhorar o trabalho dos técnicos de enfermagem. Parece difícil que o aumento do quantitativo destes profissionais possa minimizar os problemas, pois não há queixa de falta de funcionários.

Pensamos que os acompanhantes/familiares poderiam ser melhor acompanhados pela equipe de apoio, de forma pró-ativa, ou seja, tentando identificar e monitorar famílias, tirando dúvidas, dando mais explicações e avaliando as dificul- dades, antes que estes problemas cheguem aos técnicos de enfermagem.

Com relação à sensação de desproteção, percebemos que a sua desvalorização perante os médicos e à chefia é inversamente proporcional à força do cliente em instituição privada, o que acarreta muitas inseguranças profissionais, com ênfase na manutenção do emprego.

Observamos que em nenhum momento, os sujeitos da pesquisa se colocaram contra a idéia da UTI aberta e não questionaram os benefícios que a família pode trazer ao paciente. Tampouco pareceram inseguros tecnicamente perante a família. Aparentemente, não há evidências de que não gostam de trabalhar sob o olhar atento da família, como se poderia supor. Percebemos que a equipe de enfermagem tem estrutura e está segura em estar trabalhando tão próxima ao familiar/acompanhante, desempenhando seu papel. As restrições estão mais relacionadas à falta de suporte $\mathrm{e}$ valorização profissional neste ambiente.

Entendemos que a sobrecarga do enfermeiro, em desempenhar a função assistencial e administrativa, possa estar dificultando a construção de pontes entre os diferentes membros da equipe contribuindo para este cenário de dificuldades. Outro fator não menos importante é a falta de habilidade em administrar elementos ainda desconhecidos, como a presença constante de acompanhantes no cotidiano do trabalho em enfermagem, em um ambiente tradicionalmente fechado. As repercussões do ineditismo desta prática se percebem nos resultados deste trabalho, ou seja, tanto a instituição quanto os enfermeiros precisarão de um tempo para aprender a gerenciar estes conflitos até que esta proposta seja absorvida por todos os atores implicados neste processo, provocando os resultados esperados. É importante que os enfermeiros, além de gerenciar os conflitos que garantam a manutenção da proposta, mantenham uma escuta aberta, no sentido de encontrar saídas para o estabelecimento de relações mais igualitárias entre as partes e evitar/minimizar um ambiente de sofrimento no trabalho.

\section{REFERÊNCIAS}

1. Gaiva MAM, Scochi CGS. A participação da família no cuidado do prematuro em UTI neonatal. Rev Bras Enferm. 2005 Jul-Ago; 58(4):444-8.

2. Almeida FP, Veloso JWN, Blaya RP. In: Knobel E, Laselva CR, Moura Júnior DF. Terapia Intensiva Enfermagem. la ed. São Paulo (SP): Atheneu; 2006. p.39-48. 
3. Pena SB, Diogo MJD. Fatores que favorecem a participação do acompanhante no cuidado do idoso hospitalizado. Rev Latina-am Enfermagem. 2005 Set-Out; 13(5):663-9.

4. Brasil. Lei $N^{\circ} 8069$ de 13 de julho de 1990. Dispõe sobre o Estatuto da criança e do adolescente e dá outras providências. Diário Oficial da República Federativa do Brasil, Brasília, 16 jul. 1990.

5. Ministério da Saúde (BR). Parto, aborto e puerpério: assistência humanizada à mulher. Brasília (DF): Febrasgo/Abenfo; 2001.

6. Brasil. Lei $\mathrm{N}^{\circ} 10.741 \mathrm{de} 1^{\circ}$ de outubro de 2003 . Dispõe sobre o Estatuto do idoso e dá outras providências. Diário Oficial da República Federativa do Brasil, Brasília, 03 out. 2003.

7. Lamy Z. Metodologia Canguru: facilitando o encontro entre o bebê e sua família na UTI Neonatal. In: Moreira MEL, Braga NA, Morsch DS, organizadores. Quando a vida começa diferente: o bebê e sua família na UTI Neonatal. Rio de Janeiro (RJ): Fiocruz: 2003. p.141-56.

8. Ribeiro G, Nascimento AZ, Bernardino E, Oliveira ES. Limites e possibilidades da permanência de acompanhantes em unidade de Terapia Intensiva. Cogitare Enferm. 2007 Out-Dez;12(4):446-51.

9. Shimizu HE, Ciampone MHT. As representações dos técnicos e auxiliares de enfermagem acerca do trabalho em equipe na Unidade de Terapia Intensiva. Rev. Latino-am Enfermagem [periódico na Internet]. 2004 Ago [citado 2009 Abr 21]; 12(4): 623-30. Disponível em: http:/ / www.revistasusp.sibi. usp.br/scielo.php?script=sci _arttext\&pid=S010411692004000400007\&lng=pt

10. Polit DF, Hungler BP. Fundamentos de pesquisa em enfermagem. $5^{\text {a }}$ ed. Porto Alegre (RS): Artes Médicas; 2004.

11. Lefreve F, Lefreve AMC. O Discurso do sujeito coletivo: um novo enfoque em pesquisa qualitativa. $2^{\mathrm{a}}$ ed. Caxias do Sul (RS): EDUCS; 2005.
12. Ministério da Saúde (BR), Conselho Nacional de Saúde, Comissão Nacional de Ética em Pesquisa. Resolução Nº196 de 10 de outubro de 1996: diretrizes e normas regulamentadoras de pesquisas envolvendo seres humanos. Brasília (DF): MS; 1996.

13. Leite MA, Vila VSC. Dificuldades vivenciadas pela equipe multiprofissional na unidade de terapia intensiva. Rev Latino-am Enfermagem. 2005 MarAbr; 13(2):145-50.

14. Ministério da Saúde (BR), Núcleo Técnico da Política Nacional de Humanização. HumanizaSUS visita aberta e direito ao acompanhante. $2^{\mathrm{a}}$ ed. Brasília (DF): MS; 2007.

15. Silva BM, Lima FRF, Farias FSAB, Campos ACS. Jornada de trabalho: fator que interfere na qualidade da assistência de enfermagem. Texto Contexto Enferm. 2006 Jul-Set; 15(3):442-8.

16. Pinto JMS, Silva SF, Sampaio AP, Magalhães MS. A humanização da assistência na unidade de terapia intensiva na visão dos usuários. RBPS 2008; 21(2):121-7.

17. Maciel MR, Souza MF. Acompanhante de adulto na Unidade de Terapia Intensiva: Uma visão do Paciente. Acta Paul Enferm. 2006; 19(2):138-43.

18. Visintim A, Labronice L, Lenardt MH. Autonomia do paciente idoso com câncer: $\mathrm{O}$ direito de saber o diagnóstico. Acta Paul Enferm. 2007 Out-Dez; 20(4):509-13.

19. Urizzi F, Carvalho LM, Zampa HB, Ferreira GL, Grion CMC, Cardoso LTQ. Vivência de familiares de pacientes internados em unidades de terapia intensiva Rev Bras Ter Intensiva 2008; 20(4):370-5.

20. Salicio DMB, Gaiva MAM. O significado de humanização da assistência para enfermeiro que atuam em UTI. Rev Eletrônica de Enferm. 2006; 8(3):370-6. 